\title{
Spirituality Can Enhance Organizational Ethics: A Study among High School Teachers in Kochi
}

\author{
George C Mathew ${ }^{1}$, Hareesh N Ramanathan ${ }^{2}$, Minnu Susan George ${ }^{3}$ \\ ${ }^{1}$ Assistant Professor, Department of Management Studies, TocH Institute of Science and Technology, Cochin, Kerala, India \\ ${ }^{2}$ Professor and Head, Department of Management Studies, TocH Institute of Science and Technology, Cochin, Kerala, India \\ ${ }^{3}$ Student, Department of Management Studies, TocH Institute of Science and Technology, Cochin, Kerala, India
}

\begin{abstract}
Management of organizations is a key theme in socio-economic entity of the universe. Organizations of the present era confronts with the most important issues like ethical behaviour, employee commitment and employee performance. Spirituality is the worthy and effective factorwhich can improvemorality, commitment and performance. Spiritualty hasa significant impact in the life of people. Spirituality actually influences the way in which people live, behave and work. Spiritual practices could make a momentous difference in an employee's behaviour and performance in an organization.Nowadays, spiritual activities in the society are on high and we think in general, this may lead to increase in morality of the people, but in contrary there has been increase in red-tapes, corruption, nepotism, etc. Thus it is to be studied that whether spirituality can contribute ethical behaviour.
\end{abstract}

Keywords: Spirituality, Ethics, Behaviour, Organization, Culture

\section{Introduction}

Organizations in the modern era always prefer to create a congenial atmosphere which can develop a most suitable organizational culture. Organizational culture can contribute much to the enterprise for braving the stiff competition in the universal market especially in these years globalization. Creation of good and harmonious human relations is a prerequisite for the exceptional performance which is mandatory for any organization in this changing world. Good human relations motivate employees for effective and efficient business operations, promotes congenial business climate, better working environment. All these factors enable an organization to achieve the goals and objectives which envisioned for the long run.

Organizations are system which works on the basis of certain values but at the same time these organizations frequently interacts with its environment. So as an entity of the society, organizations respond strategically to the environment based on values driven by the management. The values of the organization can generally evaluated on the basis of the values uphold by the employees in that organization. The virtues and values of the chieftains in the organization will significantly contribute towards the orientation of the organization (Rendtorff, 2010). Selfunderstanding of the heads of an organization is highly critical for realizing business ethics. There is a considerable shift in the approach of spirituality driven management and traditional management. Spirituality driven management perceives employee management relation as subject to subject relation where as traditional management views employee management relation as subject to object relation.The present day management requires various expertise like vision, enthusiasm, purpose, integrity, confidence, openness, trustworthiness, and emotional intelligence (Amram, 2005).Spirituality is clandestine in its naturewhich resists precise classification (Marcel, 1950). Spirituality is different to religion in its depth and breadth
(Nelson, 2009). Many people believe that spirituality embraces religious beliefs(Hill, 2000). Spirituality always promotes connectedness. Connectedness with others as well as with the community and even with on-self is the epitome of spiriyuality(Gibbons, 2000). In a broader perspective spirituality embellishes meaning to life by enabling individuals to be more sensible in fetching directions to others as well as in keeping relations, self should be secondary in all those occasions.

Ethics is a necessary precondition for the success of any organization in the short run and a prerequisite for the long term existence of the business entity. It is the bounden duty of employees in an organization to work professionally, meticulously and morally.Unfortunately, most of the employees, irrespective of their position or level in the enterprise, finding it very difficult to be ethical. An organization requires team work, confidence and trust for its survival and growth, for which ethical behaviour is crucial. Maintaining good relations with the stake holders of the organization is the primary condition for a successful organization that can be attained only through ethical behaviour. In this era of uncertainty, interdependence and change many management theories and practices are being challenged and confronted.Perceptions of insecurity emerged in these years cannot be pin pointed to a solitary reason. In this context, a relook into the management concepts and practices.

Business entities of the modern age entice and retain creative, dynamic, talented, reliable work force that are delighted of their organizations and find solace from the employment.In today's knowledge society younger people strongly emphasize their own personal development in their choice of workplace, with such matters as title, income and opportunities for leadership roles are of lesser importance. 


\section{International Journal of Science and Research (IJSR) \\ ISSN (Online): 2319-7064}

Index Copernicus Value (2015): 78.96 | Impact Factor (2015): 6.391

\section{Literature Review}

The term spirituality exists since the abstraction of the human race. Spirituality supports emotions like unselfish love, concern, kindness, meaning, creation, inner satisfaction and self-fulfilment (Chopra, 2002). McCormick (1994) defines spirituality as one's behaviour being substantiated through an internal experience an individual has. Gibbons (2000) bestowed spirituality in the standpoint of vehementlyconcerned values. Dehler\& Welsh (1994) explain that spirituality stimulate others on the basis of inner origins of an individual. Krishnakumar\& Neck (2002) states spirituality as hereditary, which insinuate that, spirituality is an aspect or an attitude that is within of an individual. Guillory (2000) also said it as the inner consciousness which comes from individual's beliefs and values held in the sub conscious mind. Brandt (1996) also stated that spirituality goal is par excellence in understanding of individual's generic values, assisting a person in life and work to be more euphoric. Dehler\& Welsh (1994) has described spirituality in simple terms as the degree to which individual spirituality is reflected in the behaviour, attitude, perception, standards and ethics of an organization. Corrine McLaughlin (2009) opined that spirituality at business is to apply person's values of sincerity, reliability and good excellence effort. It's about intemperance of the employees in anaccurate and altruistic way. Neck and Milliman (1994) outlined that spirituality involves various steps to find meaning and purpose of life, which is instigated by personal values. McCormick (1994) as cited in Bhunia and Mukhuti (2011) explained spirituality as abehavioural exhibition ofa person'sinstinctive mental episodes. Moore and Casper (2006) also identified that spirituality is related to inbornfeatures that projectindividual behaviour.Marschke, Preziosi and Harrington (2008) noted that spirituality entaila thoroughdedication to standard norms. Organisational success is highly dependent on the degree of engagement of the hearts and minds of the employees in the work place.Mitroff and Denton (1999) highlighted that spirituality incorporate the pain to identifythe main objective in life, to instigate a strong relation to colleagues and others who associate with work, and to have a match between the beliefs and values of the workers and that of their corporations.

Ashmos\&Duchon (2000) describe spirituality as a major revolution where association focus is on community, means to provide purpose to its people within the community. Literature reveals that spirituality increases morale (Leigh, 1997), increases honesty and trust which will result in carrying out the task among employees in an improved manner (Krishnakumar\& Neck, 2002). It confers positive outlook to employees, increases their dedication level, and generates better performance (Milliman, Ferguson, Trickett\&Condemi, 1999).Earlier studies had confirmed the truth thatspirituality and religion are distinguishable (King,2007).Religiosity and spirituality have been abstracted to nurture the development of the various aspects of life. Some people believes that religiosity means have faith and respect for God, but for some others it is indulging in activities such as, regularly attending worship and actively involving in numerous communal life with their own divine fraternity (Adeyemo and Adeleye 2008.)People who follow and hold a particular religious ideology demonstrate certain peculiar conduct. This will be reflected in their personal and social lives. So it can be observed that employee's behaviour at work can also be influenced by religious affinity (Ntalianis and Darr, 2005).Many researchers and scholars have contention that spirituality, job satisfaction and the desire for meaningful work are critical factors for future organisational life. (Giacalone and Jurkiewicz, 2003; Karakas, 2009).

Kolodinsky, Giacalone\&Jurkiewicz (2008) indicated that spirituality negatively relates to organizational frustration and positively to involvement at work, organizational identification, and satisfaction at job. Saks (2006) similarly stated that job satisfaction, commitment by an employee, and organizational citizenship behaviour are an outcome of spirituality. An empirical study by Mitroff\& Denton (1999) stated an affirmative relationship between spirit at work and job satisfaction. It was concluded that it increased organizational performance in the formof higher profits and success. It has been concluded that organizations comprise of more motivated workforces if they have some type of higher meaning (Collins \&Porras, 1994; Peters \& Waterman, 1982). In order to verify the co relation between spirituality and job satisfaction and to decide the role of spirituality to their work satisfaction, a study was conducted byLazar (2010). The outcome showed a direct relationship between spirituality and job satisfaction Lazar (2010).Another study in the health care settings to cross check the relationship between spirituality and job satisfaction also revealed that the respondent's spirituality and greater self- actualization improved job satisfaction considerably .Clark et al. (2007)

Human survival is dependent on ethical behaviour. Ethics is the method of determining a course of action without which actions of humans will be purposeless and haphazard. A goal cannot be attained without a course of action. An ethical norm is required to peruse one's aim to succeed. Leaders who combine spirituality and encircle programmes from different beliefs have a benefit by enlightening their capacity to involve their employeesentirely. Various studies highlighted that business leaders who established appropriate behaviour on work place have shown profound results. Business ethics has become a major concern of most business people over the last few decades. The theoretical connection between spirituality and business ethics seems to be reasonable, experimental studieshave also ratified this argument. The insufficient experimental studies emphasises the need of moreresearch. Further studies may help in generating more abstractions about the two domains of spirituality and ethics. This gap in sufficient literature prompted to undertake a study in identifying the influence of spirituality on ethical behaviour.

\section{Research Methodology}

\subsection{Research design}

\section{[1] Descriptive design:}

The present study has under take a descriptive research to describe the situation, community, phenomena, outcome or programme. This design aims at elucidating the data and primary characteristics about the object/ situation/ concept/ under study. 
[2] Population

This study was conducted among Government High School Teachers in Kochi.

\section{[3] Sampling}

The present study adopted a convenience sampling which is a type of non-probability sampling that involves the sample being drawn from that part of the population that is close to hand. That is, a sample population selected because it is readily available and convenient, as researchers are drawing on relationships or networks to which they have easy access.

[4] Sample size

The sample size for this study was taken from teachers of various government high school in Kochi. Data was collected from around 100 respondents.

\subsection{Instrument development process}

[5] Spirituality

Spiritualitywas measured using the Spiritual Transcendence Scale (STS) developed by Piedmont (1999). The spiritual transcendence construct measured by the STS was created to be independent of existing personality models, and at the same time provide incremental validity to improve measurements of personality factors when included (Piedmont, 1999, 2001). The STS wasvalidated with both self- and observer ratings, showing that the results from the scale could be verified and have predictive value (Piedmont, 1999, 2001)

\section{[6] Ethics}

Ethics was measured by a method to that used by Singhapakdiet al.(1996, 1999), although this studyused three of the original six components of the construct proposed by Jones (1991) anddeveloped into question form by Singhapakdiet al. (1996).

Table 1: Instrument

\begin{tabular}{|c|c|}
\hline Construct & Study \\
\hline Spirituality & STS byPiedmont 1999 \\
\hline Ethics & Singhapakdiet al.(1996, 1999) \\
\hline
\end{tabular}

[7] Reliability, Validity

Reliability of this study was done by conductingcronbach's Alpha test. The alpha coefficient for the 23 items is .792, which suggests that the items have relatively high internal consistency.

Table 2: Reliability Statistics

\begin{tabular}{|c|c|}
\hline Cronbach's Alpha & N of Items \\
\hline .792 & 23 \\
\hline
\end{tabular}

[8] Tool for data collection

The tool which is used for this study was Questionnaire. A questionnaire is a research instrument consisting of a series of questions and other prompts for the purpose of gathering information from respondents relating to this study. A number of questions usually in printed form are to be answered by the Respondents. Sets of such forms are distributed to particular groups and the answers are collected relating to research topic. A Questionnaire is a structured form, either written or printed, consists of a formalized set of questions designed to collect information on some subject or subjects from one or more respondent.

In this study a structured questionnaire was used relating to the topic of the study.The first section included the questions to measure the relationship between spirituality and ethics among teachers. The second section was demographic information which contained the questions regarding age, gender, marital status, education level, Occupation, Family's Monthly Income. A 6-point scale and a 5 point Scale was used for scoring responses.

[9] Tools for analysis

Tool for analysis used were regression analysis. Regression analysis shows a relationship between the average values of two variables. Thus regression is very helpful in estimating and predicting the average value of one variable for a given value of the other variable.In this study the estimate or prediction may be made with the help of a regression line which shows the average value of one variable (Spirituality) for a given value of the other variable (Ethics).

\subsection{Regression Analysis}

\subsubsection{Spirituality and Ethics}

Hypothesis testing

$\mathrm{H} 0=$ There is no significant relation between Spirituality and Ethics.

$\mathrm{H} 1=$ There is significantrelation between Spirituality and Ethics.

Table 3: Model Summary

\begin{tabular}{|c|c|c|c|c|}
\hline Model & $\mathrm{R}$ & $\mathrm{R}$ Square & $\begin{array}{c}\text { Adjusted R } \\
\text { Square }\end{array}$ & $\begin{array}{c}\text { Std. Error of the } \\
\text { Estimate }\end{array}$ \\
\hline 1 & $.885^{\mathrm{a}}$ & .783 & .781 & 1.89158 \\
\hline \multicolumn{5}{|c|}{ a. Predictors: (Constant), SPIRITUALITY } \\
\hline
\end{tabular}

Here $\mathrm{R}=.885$ where, $\mathrm{R}$ is the square root of $\mathrm{R}$-Squared and is the correlation between the observed and predicted values of dependent variable and R Square $=.781$ where, it is the proportion of variance in the dependent variable (Ethics) which can be explained by the independent variable (Spirituality).

Table 4: ANOVA

\begin{tabular}{|c|c|c|c|c|c|c|}
\hline \multicolumn{2}{|c|}{ Model } & Sum of & Df & Mean Square & $\mathrm{F}$ & Sig. \\
\hline \multirow{3}{*}{1} & Regression & 1266.348 & 1 & 1266.348 & 353.918 & $.000^{\mathrm{b}}$ \\
\hline & Residual & 350.652 & 98 & 3.578 & & \\
\hline & Total & 1617.000 & 99 & & & \\
\hline \multicolumn{7}{|c|}{ a. Dependent Variable: ethics } \\
\hline
\end{tabular}

Since $p$-value is less than 0.01 , it implies that the calculated regression coefficient is significant and the variance in independent variable contributes to the change in dependent variable. Therefore, it is inferred that the variance in Spirituality really contribute to change in Ethics 


\section{International Journal of Science and Research (IJSR) \\ ISSN (Online): 2319-7064}

Index Copernicus Value (2015): 78.96 | Impact Factor (2015): 6.391

Table 5: Coefficients ${ }^{\mathrm{a}}$

\begin{tabular}{|c|c|c|c|c|c|c|}
\hline \multirow{2}{*}{\multicolumn{2}{|c|}{ Model }} & \multicolumn{2}{|c|}{$\begin{array}{l}\text { Unstandardized } \\
\text { Coefficients }\end{array}$} & \multirow{2}{*}{$\begin{array}{l}\text { Standardized } \\
\text { Coefficients } \\
\text { Beta }\end{array}$} & \multirow[t]{2}{*}{$\mathrm{t}$} & \multirow[t]{2}{*}{ Sig. } \\
\hline & & B & $\begin{array}{l}\text { Std. } \\
\text { Error }\end{array}$ & & & \\
\hline \multirow[t]{2}{*}{1} & (Constant) & $\begin{array}{c}- \\
14.664\end{array}$ & 2.684 & & -5.464 & .000 \\
\hline & SPIRITUALITY & .823 & .044 & .885 & 18.813 & .000 \\
\hline
\end{tabular}

The constant and parameter needed for the formulation of regression equation

$\boldsymbol{Y} \boldsymbol{i}=\boldsymbol{a}+\boldsymbol{b} \boldsymbol{X} \boldsymbol{i}$. The value given under column B against constant is the $a$-value

$(-14.664)$ and again Spirituality is the $b$-value (.823).

Therefore, regression equation $\mathrm{Yi}=\boldsymbol{a}+\boldsymbol{b} \boldsymbol{X} \boldsymbol{i}$ is formulated as,

Ethics $=-14.664+.823$ Spirituality

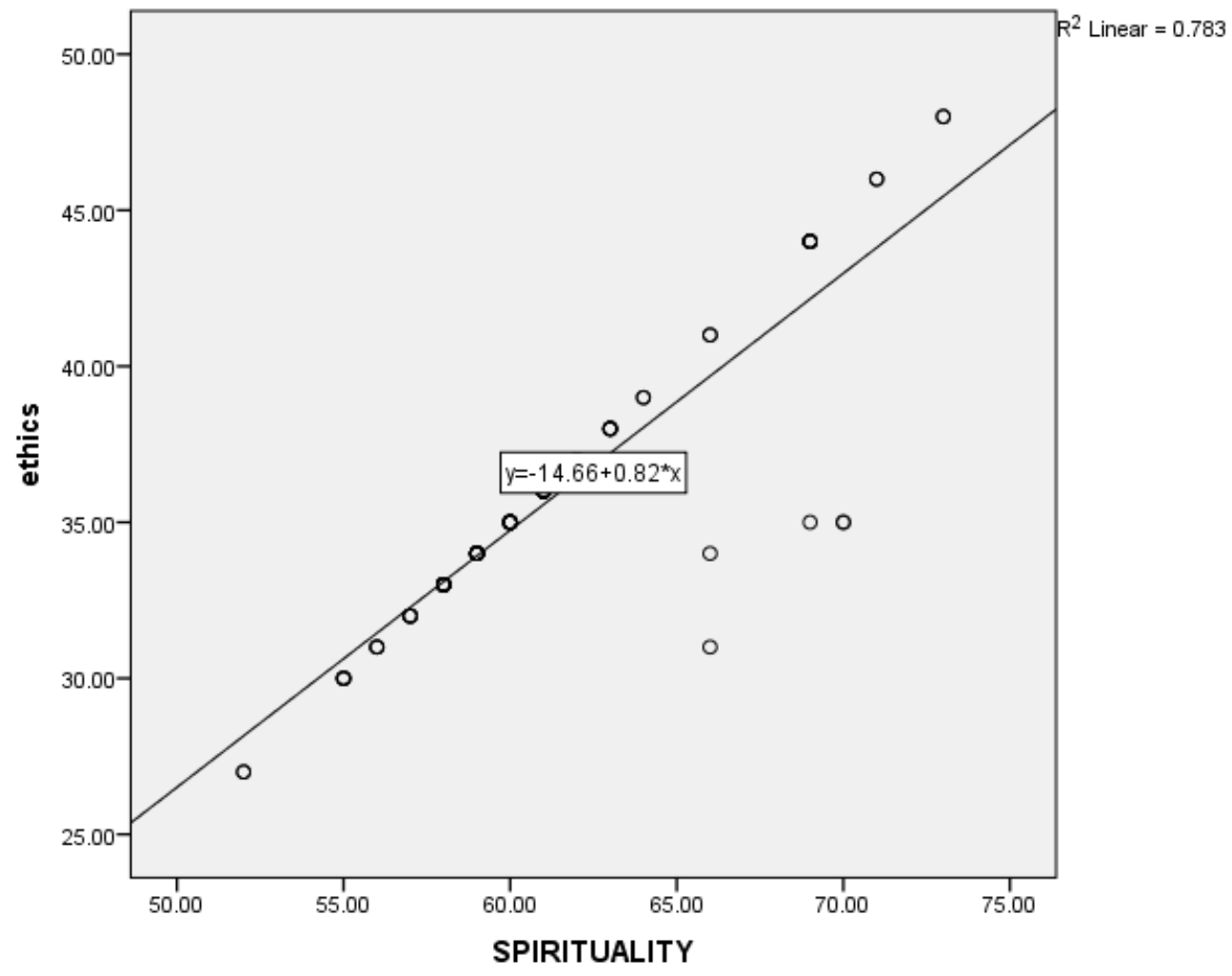

Figure 1

Here the graph shows there is a positive relation between Spirituality and Ethics

\section{Conclusion}

The present studywas set out to investigate whether spirituality in the workplace is associated with ethics, in Teaching Field. Although the relationship betweenspirituality in the workplace and ethics may seem intuitively positive, thefindings of the present study indicate that overemphasizing spirituality as afoundation for ethical direction would leave Teachers with little positive outcomes. In lights of these findings, it seems clear that Educational Institutions would benefit more by pursuing other strategies instead, such as the establishment of ethicalstandards and investing in ethical training. While contributing to forming an empiricalfoundation for future research, especially in Teachers, findings in this study will benefit from futureinvestigation that overcome the several limitations of anyresearch done in this challenging line of inquiry. As a suggestion, to improve ethical behaviour in teachers is by establishing a code of ethics. The code of ethics provides the direction and guidelines for teachers' ethical behaviour. It also helps teachers understand the institution's ethical expectations and rules.Give proper trainingto theteachers about how to behave ethically in an institution. If any teachers of the institution resorts to any malpractice or unethical behaviour after completing the ethical training, it's better to impose sanctions on them which will help teachers understand the implications of inappropriate behaviour.Therefore, the head of the department needs to lay down disciplinary actions that will be taken against teachers found guilty of violating the rules

\section{References}

[1] Adeleye, A. a. (2008). Emotional Intelligence, Religiosity and Self-Efficacy as Predictors of Psychological Well-Being among Secondary School Adolescents in Ogbomoso, Nigeria. Europe's Journal of Psychology 4(1), 40.

[2] Ashforth, B. E. (2003). . Institutionalized spirituality:An oxymoron? In R. A. Giacalone \& C. L. Jurkiewicz (Eds.). Handbook of workplace spirituality and organizational performance, 93-107.

[3] Biberman, J. a. (1997). A postmodern spiritual future for work. . Journal of Organizational Change Management, 130-138.

[4] Buchholz\& Rosenthal. (2003). Spirituality, consumption, and business: A pragmatic perspectiv. 


\section{International Journal of Science and Research (IJSR) \\ ISSN (Online): 2319-7064 \\ Index Copernicus Value (2015): 78.96 | Impact Factor (2015): 6.391}

Handbook of workplace spirituality and organizational performance, 152-163.

[5] Butts. (1999). Spirituality at Work: an Overview. Journal of Organizational Change Management, 328331.

[6] Cottingham. (2005). The Spiritual Dimension: Religion, Philosophy, and Human Value. Cambridge University Press.

[7] Davis, k. (2003). Meaning, purpose, and religiosity in at-risk youth: the relationship between anxiety and spirituality. Journal of Psychology and Theology, 356365.

[8] Dennis, H. a. (2005). Journal of Economic and Social Policy.

[9] Denton, I. I. (1999). A Study of Spirituality in the Workplace. A Spiritual Audit of Corporate America.

[10] Dew. (2008). Religion/spirituality and adolescent psychiatric symptoms: A review. Child Psychiatry Human Development, 381-398.

[11] Emmons. (1999). Striving for the Sacred: Personal Goals, Life Meaning,. Journal of Social Issues, Vol. 61, 731--745.

[12] Frohlich, M. (2001). Spiritual Discipline, Discipline of Spirituality: Revisiting Questions of Definition and Method. Spiritus A Journal of Christian Spirituality, 65-78 $\bullet$.

[13] Fry, B. a. (2011). Spirituality and Religion in the Workplace: History, Theory, and Research. Psychology of Religion and Spirituality, 175-187.

[14] Gibbons. (2000). Spirituality at work: Definitions, measures, assumptions, and validity claims. Work and Spirit: A Reader of New Spiritual Paradigms for Organizations, University of Scranton Press, Scranton, 31-111.

[15] Hamilton. (2003). Theoretical frameworks for African American women. 19-27.

[16] Hill, P. C. (2000). Conceptualizing Religion and Spirituality: Points of Commonality, Points of Departure. The Theory Of Social Behaviour, 51-77.

[17] Jurkiewicz, G. \&. (2003). Handbook of workplace spirituality and organizational performance. Toward a science of workplace spirituality, 3-28.

[18] King. (1996). Spirituality: Transformation and Metamorphosis. Religion, 343-351.

[19] Lazarus, R. S. (1984). Stress, appraisal, and coping. Newyork: Springer Publishing.

[20] Marcel. (1950). The Mystery of Being. The Harvill Press.

[21] MOHAN, D. v. (2006). Some thoughts on spirituality and. Mental Health, Religion \& Culture, 227-238.

[22] Nadesan. (1999). The discourse of corporate spiritualism and evangelical capitalism. Management Communication Quarterly, 3-42.

[23] Neal. (2001). Faith and spirituality in the workplace: Emerging research and practice. In Handbook of Faith and Spirituality in the Workplace, 3-18.

[24] Nelson. (2009). The Role of Spirituality in the Relationship Between Religiosity and Depression in Prostate Cancer Patients. Annals of Behavioral Medicine.

[25] Piedmont, R. 1. (1999). Does spirituality represent the sixth factor of personality? Spiritual transcendence and the five-factor model. JOURNAL OF PERSONALITY, 985-1013.

[26] Piedmont, R. L. (2001). Does spirituality represent the sixth factor of personality? Spiritual transcendence and the five-factor model. Journal Of Rehabilitation, 4.

[27] Plowman, D. \&. (2005). Nurturing the spirit at work: Impact on work unit performance. The Leadership Quarterly, 807-833.

[28] Rendtorff, J. D. (2010). Balancing values and economic efficiency in the public sector!: What can public welfare service institutions learn from private service firms? Society and Business Review, 293-302.

[29] Sheep. (2006). Nurturing the Whole Person:the ethics of the worksplace spirituality in a society of organizations. Journal of business Ethics, 357-375.

[30] Tischler. (1999). . The growing interest in spirituality in business. A long term socio-economic explanation. Journal of Organizational Change Management, 273280.

[31] Werner. (1984). Resilient children. Young Children, 68-72.

[32] Wilber, K. (1998). Integral Spirituality. 